\title{
An approach to creation of a unified system of programming CNC machines in the dialog mode
}

\author{
Liliya I. Martinova ${ }^{1}$, and Nikolay N. Fokin ${ }^{1, *}$ \\ ${ }^{1}$ FSBEI HPE MSTU “STANKIN”, Moscow, Russia
}

\begin{abstract}
The tendencies in the development of part programs for $\mathrm{CNC}$ machine tools are considered, the used programming methods are analysed, and the compatibility problem of interactive programming systems is proved. An approach is proposed with the use of canned cycles, which allows to unify the process of dialog programming for machines with $\mathrm{CNC}$ systems from different manufacturers. Practical aspects of creating part programs in dialog mode for machines equipped with $\mathrm{CNC}$ systems Siemens, Fanuc, Heidenhain, AxiOMA Control and Balt-Systems are presented.
\end{abstract}

\section{Introduction}

The choice of development method of the master part program - usage of the CAM-system, manual programming or $\mathrm{CNC}$ machine tools depend on exact conditions and situations, for example, type of production, the breadth of the details range, amount of the CNC systems participating in the manufacturing, qualification of the programmer-technologist [1]. CAMsystems allow program processing of any difficulty, involving usage of the detail models, eliminating the need for a programmer-technologist to carry out mathematical calculations manually. CAM-systems allow to create the part programs for various $\mathrm{CNC}$-systems using one basic language, and with that CAM-systems provide programmer-technologist with typical functions that automate a particular machining process. In order to use CAMsystems programmer-technologist uses either PC or workstation. Expensiveness of both CAM-system and additional tools for it (postprocessors, 3D-models of the machines and tools, in case if they are not included in the standard set of the CAM-system) makes them available only for large enterprises with wide range of the frequently changing details. Often the CAM-system's users face the problem of converting the design model into CAMsystem used by the programmer - some elements may not be found or to be displayed differently than intended in the design. Also, while using any special devices for fixing workpieces on the machine, it's necessary to have their 3D-models for the correct building of control trajectories, otherwise programmer would be forced to spend time on the design of those devices, which, as a result, increases the time of technological preparation of production.

Manual programming in cycles has a number of advantages before the CAM-system, for example, in case of making changes to the program. For example, while machining

*Corresponding author: nikolfokin@gmail.com 
precise cylindrical surfaces with tight tolerances for some reason an error occurred in the form of a taper and did not meet the requirements for roughness. To compensate the error while programming manually, it would be enough to add to the existing pre-emphasis circuit in the form of a reverse taper to change the flow in the loop body. But while programming in the CAM-system it is necessary to rebuild the technological model and change machining parameters, since it proves quite difficult to find the necessary frame in a long code for its editing, as in manual programming. If in order to execute these, usually simple, corrections the programmer would be forced to use the CAM-system every time, that will drastically increase the time of technological preparation of production. In situations like these, manual programming is much easier to use.

Programming on the remote control $\mathrm{CNC}$ is becoming increasingly popular due to growing development of software and hardware for CNC systems [2, 3], improvement of their interface and expansion of performed tasks: the program is created and inputted directly on the CNC rack using the keyboard and display; constant cycles are selected and inserted into the part program by using special icons, verification of the part program can be executed in parallel with the operation of another part program. Dialog programming makes the process of creating the part program even easier, and with the growing development of mobile communications, it has special prospects, in particular - remote dialog programming.

\section{The problem of compatibility of dialog programming systems}

Systems of dialog programming are greatly varied. In most cases any of these systems is single-purpose system designed to automate the programming of machining on certain equipment.

Intuitive step-by-step dialog programming editor with user-friendly interface greatly shortens time for programming for individual and small-scale production in particular, but it's usage in medium- and large-scale production appears to be less effective, and usually proves ineffective, when programming the machining of the detail with complex configuration. CNC programming language based on high-level language's commands provides maximum flexibility and minimum development time up in dialogue mode, it combines the flexibility of the language of the $\mathrm{CNC}$ and the convenience of a simple parameterization of machining cycles that provides maximum productivity $[4,5]$. For example, in CNC systems with built-in CAM-system Siemens ShopTurn and Fanuc ManualGuidei animation of machining process is applied, which provides visual support to operator, when programming the CNC system and when tracking the operation. Dialog programming on the rack is particularly useful in workshops and on site, producing the large variety of details.

Since manual programming and debugging of part programs in manual and in dialog mode takes less time than programming in CAM-systems for relatively simple parts, they can be replaced by an alternative - remote programming in dialog mode using a unified programming system, not tied to specific CNC systems [6, 7]. Similar systems exist to some extent, but they only complement the dialog programming on the rack, while using the CNC system emulator on a personal computer. Examples of such systems - Siemens Sinutrain, Fanuc NC Guide, Heidenhein Data Pilot 640, "AxiOMA Control" [8, 9, 10]. The part programs written through these systems can only work on them. 


\section{Approach to the universalization of the developed system}

To maintain the concept of universality in the system of dialogue programming for each form uses a specific set of input data based on the standard cycles of each submitted CNC system.

The full range of turning and drilling cycles of the CNC systems under consideration is presented in Table 1 .

Table 1. Turning and drilling cycles.

\begin{tabular}{|c|c|c|c|c|c|}
\hline & Siemens & Fanuc i-T & Heidenhein & AxiOMA Ctrl & Balt-System \\
\hline longitudal turning & CYCLE95 & G90 & G80 & - & $\operatorname{SPF}(Z, \ldots)$ \\
\hline face turning & CYCLE95 & G92 & G80 & - & $\operatorname{SPF}(X, \ldots)$ \\
\hline radial grooving & CYCLE93 & G75 & G870 & G288 & $\operatorname{TGL}(Z, X, \ldots)$ \\
\hline face grooving & CYCLE93 & G74 & G871 & G289 & TGL $(X, Z, \ldots)$ \\
\hline radial undercut & CYCLE95 & G71 & G835 & G281 & $\operatorname{SPF}(Z, \ldots)$ \\
\hline face undercut & CYCLE95 & G72 & G835 & $\mathrm{G} 282$ & $\operatorname{SPF}(X, \ldots)$ \\
\hline threading & CYCLE97 & G76 & G352 & G276 & FIL \\
\hline cutting & CYCLE93 & G75 & G859 & G288 & TGL $(Z, X, \ldots)$ \\
\hline $\begin{array}{c}\text { contour longitudal } \\
\text { turning }\end{array}$ & CYCLE95 & G71 & G810 & - & $\operatorname{SPF}(Z, \ldots)$ \\
\hline contour face turning & CYCLE95 & G72 & G820 & - & $\mathrm{SPF}(\mathrm{X}, \ldots)$ \\
\hline $\begin{array}{c}\text { contour parallel } \\
\text { turning }\end{array}$ & CYCLE95 & G73 & G830 & - & SPP \\
\hline centering & CYCLE81 & G85 & G71 & G81 & G81 \\
\hline drilling & CYCLE83 & G83 & G74 & G83 & G83 \\
\hline reaming & CYCLE82 & G85 & G72 & G81 & G82 \\
\hline tapping & CYCLE84 & G84 & G73 & $\begin{array}{c}\text { Tapping(“Z”,'”C } \\
,, \ldots)\end{array}$ & G84 \\
\hline
\end{tabular}

Work in the dialog mode editor (Fig. 1) is represented by the example of end groove machining programming with specified start and end points. Tool change is performed at the X200Z200 point in the machine coordinate system.

The size of the cross-cutting is defined as 0.8 of the width of the plate.

N1 Grooving

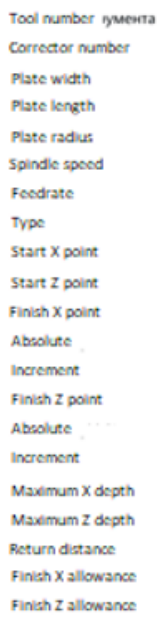
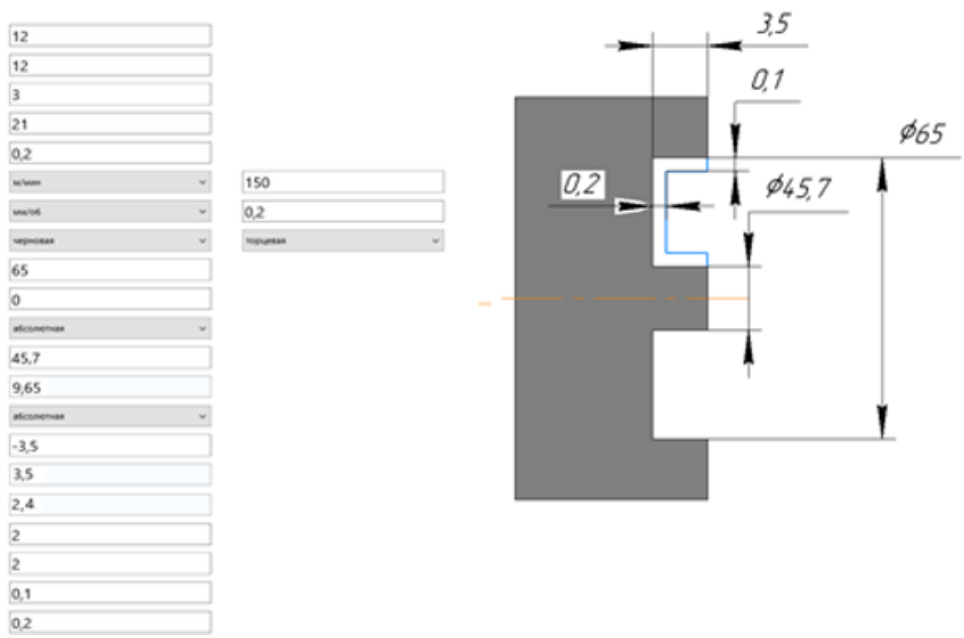

Fig. 1. Screen of editor in dialog mode. 


\section{References}

1. Martinov, G.M., Martinova, L.I. : Trends in the numerical control of machine-tool systems.Russian Eng. Res. 30(10), 1041-1045 (2010)

2. Grigoriev, S.N., Martinov, G.M.: The control platform for decomposition and synthesis of specialized CNC systems. Procedia CIRP 41, 858-863 (2016)

3. Martinov, G.M., Lyubimov, A.B., Bondarenko, A.I., Sorokoumov, A.E., Kovalev, I.A. : An approach to building a multiprotocol CNC system. Autom. Remote Control 72(10), 345-351 (2015)

4. Martinov, G.M., Ljubimov, A.B., Grigoriev, A.S., Martinova, L.I. : Multifunction numerical control solution for hybrid mechanic and laser machine tool. Procedia CIRP 1,260-264 (2012)

5. Martinova, L.I., Sokolov, S.S., Nikishechkin, P.A.: Tools for monitoring and parameter visualization in computer control systems of industrial robots. In: Tan, Y., Shi, Y., Buarque, F., Gelbukh, A., Das, S., Engelbrecht, A. (eds.) ICSI 2015. LNCS, 9141, pp. 200-207. Springer, Cham (2015)

6. Martinov, G.M., Kozak, N.V.: Numerical control of large precision machining centers by the AxiOMA contol system. Russ. Eng. Res. 35(7), 534-538 (2015)

7. Grigoriev, S. and Martinov, G. An ARM-based Multi-channel CNC Solution for Multitasking Turning and Milling Machines. Procedia CIRP, 46, pp.525-528 (2016)

8. Martinova, L., Kozak, N., Nezhmetdinov, R., Pushkov, R. and Obukhov, A. The Russian multi-functional CNC system AxiOMA control: Practical aspects of application. Automation and Remote Control, 76(1), pp.179-186. (2015)

9. Martinov, G., Obuhov, A., Martinova, L. and Grigoriev, A. An Approach to Building Specialized CNC Systems for Non-traditional Processes. Procedia CIRP, 14, pp.511516 (2014)

10. Martinov, G., Kozak, N., Nezhmetdinov, R., Grigoriev, A., Obukhov, A. and Martinova, L. Method of decomposition and synthesis of the custom CNC systems. Automation and Remote Control, 78(3), pp.525-536 (2017) 